\title{
Ruling out intra-abdominal injuries in blunt trauma patients using clinical criteria and abdominal ultrasound
}

\section{Exclusão de lesões intra-abdominais em vítimas de trauma fechado através de variáveis clínicas e ultrassom abdominal completo}

Flávia Helena Barbosa Moura, AsCBC-SP1; José Gustavo Parreira, TCBC-SP2,3; Thiara Mattos4; Giovanna Zucchini Rondiñ4; Cristiano Below ${ }^{4}$; Jacqueline Arantes G. Perlingeiro, TCBC-SP2,3; Silvia Cristine Solda, TCBC-SP2,3; José Cesar Assef, TCBC-SP2,3.

\begin{abstract}
A B S T R A C T
Objective: to identify victims of blunt abdominal trauma in which intra-abdominal injuries can be excluded by clinical criteria and by complete abdominal ultrasonography. Methods: retrospective analysis of victims of blunt trauma in which the following clinical variables were analyzed: hemodynamic stability, normal neurologic exam at admission, normal physical exam of the chest at admission, normal abdomen and pelvis physical exam at admission and absence of distracting lesions (Abbreviated Injury Scale $>2$ at skull, thorax and/or extremities). The ultrasound results were then studied in the group of patients with all clinical variables evaluated. Results: we studied 5536 victims of blunt trauma. Intra-abdominal lesions with AIS>1 were identified in 144 (2.6\%); in patients with hemodynamic stability they were present in 86 (2\%); in those with hemodynamic stability and normal neurological exam at admission in 50 (1.8\%); in patients with hemodynamic stability and normal neurological and chest physical exam at admission, in 39 (1.5\%); in those with hemodynamic stability, normal neurological, chest, abdominal and pelvic physical exam at admission, in 12 (0.5\%); in patients with hemodynamic stability, normal neurological, chest, abdominal and pelvic physical exam at admission, and absence of distracting lesions, only two (0.1\%) had intra-abdominal lesions. Among those with all clinical variables, 693 had normal total abdominal ultrasound, and, within this group, there were no identified intra-abdominal lesions. Conclusion: when all clinical criteria and total abdominal ultrasound are associated, it is possible to identify a group of victims of blunt trauma with low chance of significant intra-abdominal lesions.
\end{abstract}

Keywords: Abdominal Injuries. Delayed Diagnosis. Diagnosis. Ultrasonography. External Causes. Multiple Trauma.

\section{INTRODUCTION}

In Brazil, in 2015, more than 152,000 people lost their lives due to external causes ${ }^{1}$. However, this is just one of the aspects of this problem². During acute phase, costs of medical care, hospitalization, exams and treatment must also be taken into account. It is expected that, in a broad sample of victims with blunt trauma, $2 \%$ to $3 \%$ have intra-abdominal lesions $(\mathrm{IAL})^{3}$. Even in asymptomatic patients with normal physical exam, it is possible to find potentially lethal intra-abdominal lesions. This is one of the reasons why we consider nondiagnosed intra-abdominal lesions a frequent cause of "preventable" death in trauma patients. Therefore, image exams had been progressively introduced in the evaluation of victims of blunt trauma.
At present, FAST (Focused Assessment Sonography for Trauma) is one of the first methods that can be used. This method uses ultrasound to detect free liquid at the abdominal cavity. However, a negative exam does not exclude IAL. Also, total abdominal ultrasound, aside from free liquid, detects visceral lesions. It is performed by radiologists, since the learning curve is much longer. Total US presents, as main advantages, its low cost, availability, portability, the chance to reexam several times the same patient, and the lack of use of ionizing radiation or contrast. It may also present false-negative results, since it depends on the examiner and not always detects minor bleeding or intraperitoneal lesions ${ }^{4,5}$. Its result may be compromised by gas interposition, obesity or empty bladder. Literature data show that US may fail in up to $10 \%$

1 - Irmandade da Santa Casa de Misericórdia de São Paulo, Department of Surgery, São Paulo, SP, Brazil. 2 - Irmandade da Santa Casa de Misericórdia de São Paulo, Emergency Department, São Paulo, SP, Brazil. 3 - Faculty of Medical Sciences of Santa Casa de São Paulo, Department of Surgery, São Paulo, SP, Brazil. 4 - Faculty of Medical Sciences of Santa Casa de São Paulo, Medical School, São Paulo, SP, Brazil. 
patients ${ }^{6,7}$

Computer tomography (CT) has a sensitivity of $99 \%$ in some studies and is considered a better accurate method to diagnose traumatic intra-abdominal lesions, but also with disadvantages and limitations. CT not always detects pancreatic and intestinal lesions $^{8}$. Also, when compared to abdominal ultrasound, is less available, with higher cost, with no portability and with the risks of ionizing radiation and use of iodinated contrast ${ }^{9-12}$. Therefore, the attending physician must know how to use these image methods optimally, balancing their advantages and disadvantages. In a large trauma center, the optimized use of US saves costs of more expensive exams and non-therapeutic procedures.

We hypothesize that the association of clinical variables and total abdominal ultrasound may be used to exclude intra-abdominal lesions in victims of blunt trauma, lowering the need of abdominal Ct. Therefore, the objective of our study is to evaluate the association of several clinical variables and abdominal ultrasound to exclude intra-abdominal lesions in victims of blunt trauma.

\section{METHODS}

This study was approved by the Research Ethical Committee of Irmandade da Santa Casa de São Paulo, \# 59542816.2.0000.5479. We performed a retrospective analysis of information at the data bank of the Emergency Department, that were prospectively collected using standardized protocols of quality control, from 2008 to 2010.

In the study, we included victims of blunt trauma with more than 14 years old. We revised identification, trauma mechanism, general condition at admission, exams, lesions, treatment and complications. Severity of trauma and lesions were stratified by the following scores: Coma Glasgow Scale (CGS), Revised Trauma Score (RTS), Abbreviated Injury Scale (AIS), Organ Injury Scale (OIS) and Injury Severity Score (ISS) ${ }^{13}$.

The routine protocol of objective evaluation of abdomen of victims of blunt trauma in our Emergency Department includes initial physical exam, image and laboratory exams. Image exams include FAST,
US and CT; the latter is selectively obtained depending on the risk evaluation of abdominal lesion of the attending physician. Laboratory tests include white cells count, serum amylase, arterial blood gases, according to severity of trauma. Leukocytosis, hyperamylasemia and metabolic acidosis (base deficit inferior to $-6 \mathrm{mEq} / \mathrm{L}$ ) suggest the presence of lesions eventually not identified by the image exams.

In our study, we selected clinical variables evaluated at admission: hemodynamic stability (HS), normal neurological exam at admission (NNEx), normal chest physical exam (NTEx), normal abdominal and pelvic physical exam (NAPEx) and absence of distracting lesions ( $A D L)$. HS was considered when $\mathrm{SBP}>100 \mathrm{mmHg}$ and $C R<100 \mathrm{bpm}$. NNEx was considered when patient was conscious, oriented, Coma Glasgow Scale 15. NTEx was considered when physical exam showed no signs of thoracic trauma and patients had no symptoms of thoracic lesions. NAPEx was considered when patient was asymptomatic and abdominal and pelvic physical exams showed no pain or signs of local trauma (bruises, escorting, hematomas). Distracting lesions were those AIS $>2$ at skull, thorax or extremities.

Those criteria were progressively overlapped to select the group with the smallest possibility to present IAL with AIS $>1$. Those variables are easily identified during initial evaluation of trauma patients, and are useful tools for decision making. They were determined by the most senior surgical resident (R3/R4) along with attending physicians. After that, we analyzed the US results in the group of patients with all clinical evaluated variables.

We also performed a comparison of frequency of IAL with AIS>1 among patients with or without evaluated variables, using the chi-square test, considering statistically significant when $p<0.05$. We calculated the Odds Ratio and 95\% confidence interval for absence of intra-abdominal lesions according to clinical variables.

The above mentioned variables were included in a logistic regression by the "Enter" method, to identify a predictive model of "absence" of intra-abdominal lesions. We calculated the area under the curve ROC (Receiver Operating Characteristic) to estimate the ac- 
curacy of the model obtained by logistic regression.

\section{RESULTS}

During the studied period, 5536 patients victims of blunt abdominal trauma were consulted. IAL were identified in 172 patients (3.1\%). Of patients with abdominal AIS>1, there were 144 (2.6\%) patients with IAL, mainly parenchymal organs (Table 1 ).

Table 1. AIS>1 intra-abdominal lesions in 144 patients victims of blunt trauma.

\begin{tabular}{lc}
\hline Inflicted organ & Number $(\%)$ \\
\hline Spleen & $54(37.5)$ \\
Liver & $50(34.7)$ \\
Kidneys & $21(14.5)$ \\
Small intestine & $10(6.9)$ \\
Colon & $1(0.7)$ \\
Bladder & $8(5.5)$ \\
\hline Total & $144(100.0)$ \\
\hline
\end{tabular}

Considering only the 4290 patients with HS, IAB were present in 86 (2\%). In 2834 patients with HS and NNEx, IAL were diagnosed in 50 (1.8\%). In 2577 patients with HS, NNEX and NTEX, IAL were present in 39 (1.5\%). Of 2356 patients with HS, NNEx, NTEx and NAPEx, IAL were found in $12(0.5 \%)$. Of 2031 patients with HS, NNEx, NTEx, NAPEx and ADL, only two had IAL (two splenic lesions: one not treated by surgery and another submitted to splenectomy) (Table 2).

In the group with all clinical variables, 693 had normal US, and, in this group, there were no IAL. In patients with abdominal AIS $>1$ submitted to US according to our protocol, US reached $94.6 \%$ of positivity, identifying 71 of 75 possible IAL (Table 3).

At figure 1, we observed the comparison of frequency of $I A L$ with AIS $>1$ among patients with and without studied clinical variables. All comparisons were statistically significant, $p<0.001$. The highest
Odds Ratio for absence of IAL with AIS $>1$ was normal abdominal exam: 12.1 (8.9 to 16.6). The created predictive model by logistic regression (Table 4) reached an area under the curve (AUC) of 0.898 (accuracy of $89.8 \%$ ) (Figure 2).

Table 2. Association of analyzed variables and frequency of intra-abdominal lesions.

\begin{tabular}{lll}
\hline Variable & $\begin{array}{c}\text { Number of } \\
\text { patients }\end{array}$ & $\begin{array}{l}\text { IAL } \\
\text { frequency } \\
(\%)\end{array}$ \\
\hline HS & 4290 & $86(2.0)$ \\
NNEx & 3419 & $78(2.3)$ \\
NTEx & 4998 & $117(2,3)$ \\
NAPEx & 4945 & $73(1.5)$ \\
ADL & 4431 & $64(1.4)$ \\
HS + NNEx & 2834 & $50(1.8)$ \\
HS + NNEx + NTEx & 2577 & $39(1.5)$ \\
HS + NNEx + NTEx + & 2356 & $12(0.5)$ \\
NAPEx & & \\
HS + NNEx + NTEx + & 2031 & $4(0.2)$ \\
NAPEx + ADL & &
\end{tabular}

HS: hemodynamic stability; NNEx: normal neurological exam at admission; NTEX: normal thorax exam at admission; NAPEx: normal abdominal and pelvic exams at admission; $A D L$ : absence of distracting lesions.

Table 3. Abdominal ultrasound positivity to intra-abdominal lesions $(A / S>1)$.

$\begin{array}{lcl}\text { Inflicted organ } & \text { total US } & \text { Positive } \\ \text { (absolute number) } & \text { (performed) } & \text { US n (\%) }\end{array}$

\begin{tabular}{lcl}
\hline Liver (50) & 28 & $27(96.4)$ \\
Spleen (54) & 33 & $32(96.9)$ \\
Kidney (21) & 9 & $8(88.9)$ \\
Small intestine (10) & 3 & $2(66.7)$ \\
Bladder (8) & 2 & $2(100.0)$ \\
\hline Total & 75 & $71(94.6)$ \\
\hline
\end{tabular}


Table 4. Logistic regression by the "Enter" method of analyzed variables.

\begin{tabular}{|c|c|c|c|c|c|c|c|}
\hline & & \multicolumn{6}{|c|}{ Variables in the Equation } \\
\hline & & B & S.E. & Wald & df & Sig. & $\operatorname{Exp}(B)$ \\
\hline \multirow[t]{6}{*}{ Etep1a } & NNEx (1) & .122 & .190 & .412 & 1 & .521 & 1.130 \\
\hline & HS (1) & .918 & .192 & 22.923 & 1 & .000 & 2.504 \\
\hline & NTEx (1) & .495 & .208 & 5.690 & 1 & .017 & 1.641 \\
\hline & NAPEx (1) & 2.436 & .183 & 176.290 & 1 & .000 & 11.427 \\
\hline & ADL (1) & 1.809 & .190 & 90.543 & 1 & .000 & 6.107 \\
\hline & Constant & 5.235 & .183 & 814.404 & 1 & .000 & .005 \\
\hline
\end{tabular}

Variables entered on step 1: NNEx: normal neurological exam at admission; HS: hemodynamic stability; NTEx: normal chest exam at admission; NAPEx: normal abdominal and pelvic exam at admission; ADL: absence of distractive lesions.

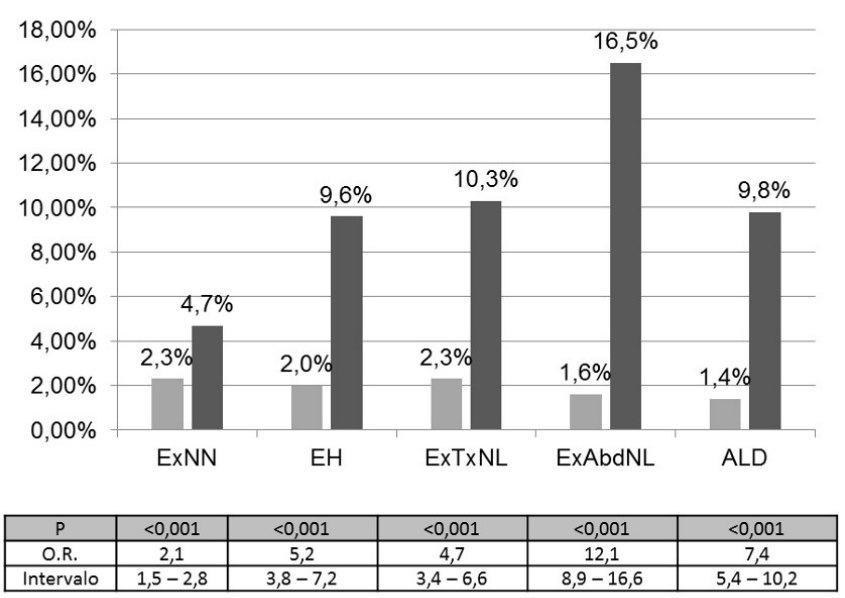

Figure 1. Comparison of frequency of $\mid A L>1$ among groups. O.R.: Odds ratio. $95 \%$ Confidence Interval.

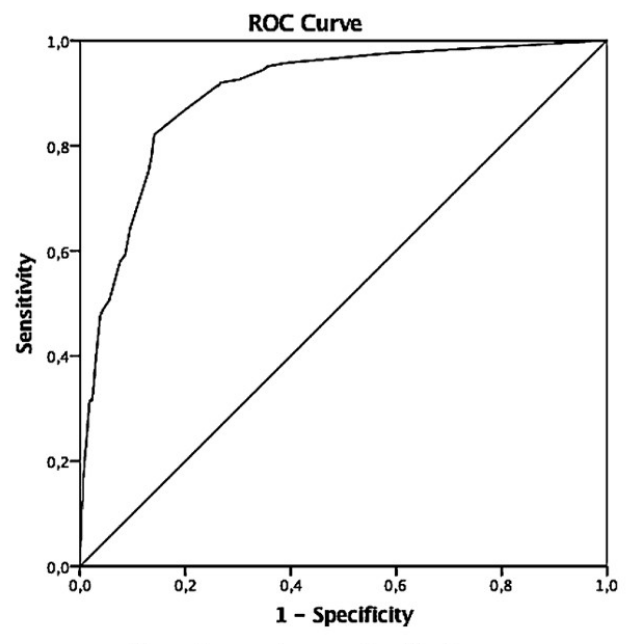

Diagonal segments are produced by ties.

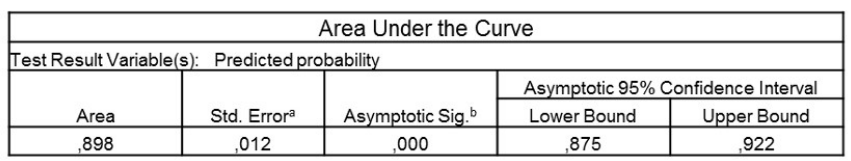

Figure 2. ROC curve for the model with clinical variables. AUC: area under the curve ROC.

\section{DISCUSSION}

Trauma is a disease where it is observed exchange of energy between external environment and human body, that may cause lesions in all organism. It is a World epidemics. Trauma disease is the major cause of loss of productive years, since it afflicts mainly young people in most productive years ${ }^{2}$. Early identification and treatment of lesions assure better prognosis. Our data confirm low frequency of intra-abdominal lesions in a cohort of victims of blunt trauma (2.6\%). However, the analysis of such lesions show that they could add morbidity and mortality if not identified on time.

Many studies tried to stablish guidelines to exclude intra-abdominal lesions using clinical criteria $a^{3,12,14-18}$. These clinical markers were capable to indicate the presence of intra-abdominal lesions, but with low performance to exclude them. In clinical practice, "exclusion" of IAL is a very frequent problem. This is the reason why image methods are used to complement correct abdominal evaluation in victims of blunt trauma.

$\mathrm{CT}$ is the gold-standard exam to identify possible IAL, with up to $99 \%$ of sensitivity. However, it has some disadvantages: higher cost and long hospitalization time. In centers with high daily number of patients, the use of CT must be efficient, without a significant number of negative exams during evaluation of victims of blunt trauma; also, it exposes patients to ionizing radiation, and present risks inherent to the use of intravenous contrast. At present, the best protocol 
for selective use of CT based on clinical, laboratorial and image methods (such as FAST and US), 3,9-12 has not been determined. Among these, FAST is the method with lower sensitivity. However, it is the only available resource in the trauma room, important in hemodynamically unstable patients. Usually, FAST does not identify $25 \%$ of IAL, and its accuracy varies from 60 to $80 \%{ }^{3,19}$. US has a sensitivity of up to $90 \%$ if performed by a talented radiologist. When we associate US to clinical variables, sensitivity reach that of $C T$, as shown by some studies $3,5,6,15,20$.

Our objective met this necessity. We believe that the use of clinical variables and associated total abdominal US may present an adequate accuracy. When we chose those clinical variables, we observed practicality. We selected those that could be evaluated at trauma room without the need of complex resources. During initial evaluation, we observe hemodynamics status, and perform thoracic, abdominal, neurological and extremities exams. In front of doubtful evaluation of thorax or pelvis exams, X-rays may be ordered. Therefore, during initial consultation, it is possible to identify the following variables: hemodynamic stability (HS), normal neurological exam at admission (NNEx), normal chest exam at admission (NTEx), normal abdominal and pelvic physical exam at admission (NAPEx) and absence of distracting lesions (ADL).

The choice of these variables took into account previous studies that associated the presence of intra-abdominal lesions to hemodynamic stability, thoracic lesions, as well as pelvic, extremities and intracranial lesions ${ }^{12}$. It is important to highlight that abdominal physical exam may be normal, even in patients with potentially lethal intra-abdominal lesions. This can be explained by the presence of associated cranial-encephalic trauma (CET), distracting lesions or use of sedatives at admission (for example, for oral-tracheal intubation) that can misguide clinical exam ${ }^{18,21}$. Therefore, the doubt to perform image exams is observed in patients with normal abdominal exam but with other indicators of abdominal lesion.

Sharples and Brohi'22, in 2016, revised literature and identified seven important studies. Sensitivity of several tools to detect intra-abdominal lesions varied from $86 \%$ to $100 \%$. In our study, the sequential addi- tion of studied variables (HS + NNEx + NTEx + NAPEx + $A D L$ ) resulted in a frequency of $0.1 \%$ of abdominal lesions. If associated to US, all lesions with AIS >1 would be identified (100\% sensitivity).

Holmes et al. ${ }^{23}$, in 2009, evaluated a model that included clinical data (Glasgow Coma Scale $<14$, pain at costal arches, abdominal pain and femur fracture) and laboratory tests such as hematocrit and urine exam. This study, that included 1595 patients during validation phase, presented a tool with negative predictive value of $98.6 \%$. In our analysis, we chose not to include laboratory exams, that would add a significant time to the process. Even without these exams, we had a significant accuracy.

Nishijima et al. ${ }^{24}$, in 2012, add to clinical and laboratory exams the results of bedside ultrasound. These authors reported that the presence of intra-abdominal free liquid was the best marker of lesion, overcoming clinical data and laboratory exams. However, the absence of liquid did not exclude the presence of intra-abdominal lesions. This study reinforces the idea to associate clinical data and image exams, such as in our study and of other authors ${ }^{15}$.

Chardoli et al. ${ }^{25}$, in 2017 used the absence of clinical markers, ultrasound (FAST) and laboratory alterations in intra-abdominal lesions as a criteria for hospital discharge of patients victims of blunt trauma without CT. These authors interviewed by phone these patients after one week and none of 158 patients had symptoms of undiagnosed abdominal lesions. Our data also favor the identification of a subgroup of victims of blunt trauma with minimal chance of intra-abdominal lesions that could be discharged without CT scan. This would optimize the available resources of crowded emergency centers without compromising patient safety. There are data that show that significant IAL are apparent up to nine hours after trauma ${ }^{26}$. Maybe this variable can be included in future studies in order to also limit the use of abdominal ultrasound in these patients.

Although with interesting results, we must emphasize some limitations of our study. It is a retrospective study, and there are nuances in the definition of the studied variables. For example, in elderly people, hemodynamic stability may be interpreted differently. 
There may be also possible disagreement of a particular variable by the attending physicians. One of the major limitations is the lack of a "true" negative result, that is, our protocol may have not identified lesions and we were not informed of new admissions for that reason. since our team is responsible for daily follow up of all victims of trauma, probably we would be aware of this fact. Also, other studies are needed, particularly prospective, to validate our data.

Our final message is that it is possible to associate clinical variables and US to exclude IAL with AIS $>1$ in victims of blunt trauma.

\title{
R E S U M O
}

\begin{abstract}
Objetivo: identificar vítimas de trauma fechado de abdome nas quais as lesões intra-abdominais possam ser excluídas por critérios clínicos e por ultrassonografia abdominal completa. Métodos: análise retrospectiva de vítimas de trauma fechado em que se analisou as seguintes variáveis clínicas: estabilidade hemodinâmica, exame neurológico normal à admissão, exame físico do tórax, do abdome e da pelve normais à admissão e ausência de lesões distrativas (Abbreviated Injury Scale $>2$ em crânio, tórax e/ou extremidades). Em seguida estudou-se o resultado da ultrassonografia no grupo de pacientes com todas as variáveis clínicas avaliadas. Resultados: estudamos 5536 vítimas de trauma fechado. Lesões intra-abdominais com AIS>1 foram identificadas em 144 (2,6\%) casos; em pacientes com estabilidade hemodinâmica, estavam presentes em 86 (2\%); naqueles com estabilidade hemodinâmica e exame neurológico normal à admissão em 50 (1,8\%); nos casos com estabilidade hemodinâmica, exame neurológico e do tórax normais à admissão em 39 (1,5\%); em pacientes com estabilidade hemodinâmica e com exame neurológico, do tórax, do abdome e da pelve normais em 12 (0,5\%); naqueles com estabilidade hemodinâmica e com exame neurológico, do tórax, do abdome e da pelve normais e ausência de lesões distrativas, em apenas dois $(0,1 \%)$ pacientes. Nos pacientes com todas as variáveis clínicas, 693 apresentavam ultrassonografia abdominal completa normal e, neste grupo, não foram identificadas lesões intra-abdominais posteriormente. Conclusão: pela somatória de critérios clínicos e ultrassonografia abdominal completa, é possível identificar um grupo de vítimas de trauma fechado com baixa chance de apresentar lesões intra-abdominais significativas.
\end{abstract}

Descritores: Traumatismos Abdominais. Diagnóstico Tardio. Diagnóstico. Ultrassonografia. Causas Externas. Traumatismo Múltiplo.

\section{REFERENCES}

1. Brasil. Ministério da Saúde. DATASUS. Indicadores de mortalidade: óbitos por causa externa [Internet]. Brasília (DF): Ministério da Saúde; 2015 [citado 2017 Aug 2017]. Disponível em: http://tabnet.datasus.gov. br/cgi/tabcgi.exe?sim/cnv/ext10uf.def

2. Reichenheim ME, de Souza ER, Moraes $C L$, de Mello Jorge MH, da Silva CM, de Souza Minayo MC. Violence and injuries in Brazil: the effect, progress made, and challenges ahead. Lancet. 2011;377(9781):1962-75.

3. Farrath $S$, Parreira JG, Olliari CB, Silva MA, Perlingeiro JA, Soldá SC, et al. Identifying severe abdominal injuries during the initial assessment in blunt trauma patients. Rev Col Bras Cir. 2013;40(4):305-11.

4. Stengel D, Rademacher G, Ekkernkamp A, Güthoff C, Mutze S. Emergency ultrasound-based algorithms for diagnosing blunt abdominal trauma. Cochrane Database Syst Rev. 2015;(9):CD004446.

5. Feyzi A, Rad MP, Ahanchi N, Firoozabadi J. Diagnostic accuracy of ultrasonography in detection of blunt abdominal trauma and comparison of early and late ultrasonography 24 hours after trauma. Pak J Med Sci.
2015;31(4):980-3.

6. Brown MA, Sirlin CB, Hoyt DB, Casola G. Screening ultrasound in blunt abdominal trauma. J Intensive Care Med. 2003;18(5):253-60.

7. Nural MS, Yardan T, Güven H, Baydin A, Bayrak IK, Kati C. Diagnostic value of ultrasonography in the evaluation of blunt abdominal trauma. Diagn Interv Radiol. 2005;11(1):41-4.

8. Melamud K, LeBedis CA, Soto JA. Imaging of Pancreatic and Duodenal Trauma. Radiol Clin North Am. 2015;53(4):757-71, viii.

9. Colling KP, Irwin ED, Byrnes MC, Reicks P, Dellich WA, Reicks K, et al. Computed tomography scans with intravenous contrast: low incidence of contrast-induced nephropathy in blunt trauma patients. J Trauma Acute Care Surg. 2014;77(2):226-30.

10. James MK, Schubl SD, Francois MP, Doughlin GK, Lee SW. Introduction of a pan-scan protocol for blunt trauma activations: what are the consequences? Am J Emerg Med. 2017;35(1):13-19.

11. Radwan MM, Abu-Zidan FM. Focussed Assesment Sonograph Trauma (FAST) and CT scan in blunt abdominal trauma: surgeon's perspective. Afr Health 
Sci. 2006;6(3):187-90.

12. Farrath S, Parreira JG, Perlingeiro JA, Solda SC, Assef JC. Predictors of abdominal injuries in blunt trauma. Rev Col Bras Cir. 2012;39(4):295-300.

13. Pereira Jr GA, Scarpelini S, Basile-Filho A, Andrade J. Índices de trauma. Medicina, Ribeirão Preto. 1999;32(3):237-50.

14. Deunk J, Brink M, Dekker HM, Kool DR, van Kuijk C, Blickman JG, et al. Routine versus selective computed tomography of the abdomen, pelvis, and lumbar spine in blunt trauma: a prospective evaluation. J Trauma. 2009;66(4):1108-17.

15. Dehqanzada ZA, Meisinger Q, Doucet J, Smith A, Casola G, Coimbra R. Complete ultrasonography of trauma in screening blunt abdominal trauma patients is equivalent to computed tomographic scanning while reducing radiation exposure and cost. J Trauma Acute Care Surg. 2015;79(2):199-205.

16. Mackersie RC, Tiwary AD, Shackford SR, Hoyt DB. Intraabdominal injury following blunt trauma. Identifying the high-risk patient using objective risk factors. Arch Surg.1989;124(7):809-13.

17. Deunk J, Brink M, Dekker HM, Kool DR, Blickman JG, van $V$ ugt $A B$, et al. Predictors for the selection of patients for abdominal CT after blunt trauma: a proposal for a diagnostic algorithm. Ann Surg. 2010;251(3):512-20.

18. Karamercan A, Yilmaz TU, Karamercan MA, Aytaç B. Blunt abdominal trauma: evaluation of diagnostic options and surgical outcomes. Ulus Travma Acil Cerrahi Derg. 2008;14(3):205-10.

19. Richards JR, McGahan JP. Focused Assessment with Sonography in Trauma (FAST) in 2017: what radiologists can learn. Radiology. 2017;283(1):30-48.

20. Brown MA, Casola G, Sirlin CB, Patel NY, Hoyt DB. Blunt abdominal trauma: screening us in 2,693 patients. Radiology. 2001;218(2):352-8.

21. Parreira JG, Malpaga JMD, Olliari CB, Perlingeiro JAG, Soldá SC, Assef JC. Predictors of "occult" intraabdominal injuries in blunt trauma patients. Rev Col Bras Cir. 2015;42(5):311-7.

22. Sharples A, Brohi K. Can clinical prediction tools predict the need for computed tomography in blunt abdominal? A systematic review. Injury. 2016;47(8):1811-8.

23. Holmes JF, Wisner DH, McGahan JP, Mower WR, Kuppermann N. Clinical prediction rules for identifying adults at very low risk for intra-abdominal injuries after blunt trauma. Ann Emerg Med. 2009;54(4):575-84.

24. Nishijima DK, Simel DL, Wisner DH, Holmes JF. Does this adult patient have a blunt intra-abdominal injury? JAMA. 2012;307(14):1517-27.

25. Chardoli M, Rezvani S, Mansouri P, Naderi K, Vafaei A, Khorasanizadeh $\mathrm{M}$, et al. Is it safe to discharge blunt abdominal trauma patients with normal initial findings? Acta Chir Belg. 2017;117(4):211-215.

26. Jones EL, Stovall RT, Jones TS, Bensard DD, Burlew CC, Johnson JL, et al. Intra-abdominal injury following blunt trauma becomes clinically apparent within 9 hours. J Trauma Acute Care Surg. 2014;76(4):1020-3.

Received in: 15/08/2017

Accepted for publication: 28/09/2017

Conflict of interest: none.

Source of funding: none.

\section{Mailing address:}

José Gustavo Parreira

E-mail: jgparreira@uol.com.br / mcmassef@uol.com.br 